\title{
Is ITS-2 rDNA suitable marker for genetic characterization of Sarcoptes mites from different wild animals in different geographic areas?
}

\author{
S. Alasaad ${ }^{\text {a,b }}$, D. Soglia ${ }^{\text {b }}$, V. Spalenza ${ }^{\text {b }}$, S. Maione ${ }^{\mathrm{b}}$, R.C. Soriguer ${ }^{\mathrm{c}}$, J.M. Pérez $^{\mathrm{a}}$, \\ R. Rasero ${ }^{b}$, M.P. Ryser Degiorgis ${ }^{\mathrm{d}}$, H. Nimmervoll ${ }^{\mathrm{d}}$, X.Q. Zhu ${ }^{\mathrm{e}, *}$, L. Rossi ${ }^{\mathrm{b}, * *}$ \\ a Departamento de Biología Animal, Biología Vegetal y Ecología, Universidad de Jaén, Campus Las Lagunillas, s.n., E-23071 Jaén, Spain \\ ${ }^{\mathrm{b}}$ Dipartimento di Produzioni Animali, Epidemiologia ed Ecologia, Università degli Studi di Torino, Via Leonardo da Vinci 44, I-10095 Grugliasco, Italy \\ ${ }^{\mathrm{c}}$ Estación Biológica de Doñana (CSIC), Av. María Luisa, s.n., Pabellón del Perú, E-41013 Sevilla, Spain \\ ${ }^{\mathrm{d}}$ Centre for Fish and Wildlife Health, Institute of Animal Pathology, Vetsuisse Faculty Berne, Berne, Switzerland \\ ${ }^{\mathrm{e}}$ College of Veterinary Medicine, South China Agricultural University, 483 Wushan Street, Tianhe District, Guangzhou, Guangdong Province 510642, PR China
}

\section{A R T I C L E I N F O}

\section{Article history:}

Received 13 August 2008

Received in revised form 3 October 2008

Accepted 3 October 2008

\section{Keywords:}

Europe

Genetic characterization

Genotypes

Ribosomal DNA (rDNA)

Second internal transcribed spacer (ITS-2) Sarcoptes scabiei

Wildlife

\begin{abstract}
A B S T R A C T
The present study examined the relationship among individual Sarcoptes scabiei mites from 13 wild mammalian populations belonging to nine species in four European countries using the second internal transcribed spacer (ITS-2) of nuclear ribosomal DNA (rDNA) as genetic marker. The ITS-2 plus primer flanking 5.8S and 28S rDNA (ITS-2+) was amplified from individual mites by polymerase chain reaction (PCR) and the amplicons were sequenced directly. A total of 148 ITS-2+ sequences of $404 \mathrm{bp}$ in length were obtained and 67 variable sites were identified (16.59\%). UPGMA analyses did not show any geographical or host-specific clustering, and a similar outcome was obtained using population pairwise Fst statistics. These results demonstrated that ITS-2 rDNA does not appear to be suitable for examining genetic diversity among mite populations.
\end{abstract}

(c) 2008 Elsevier B.V. All rights reserved.

\section{Introduction}

Sarcoptes scabiei was probably originated as a human parasite and man spread the infection to domestic animals (Fain, 1978). Various wildlife species in turn were infected, often from contact with their domestic counterparts (Pence and Ueckermann, 2002). Sarcoptes mite infections are endemic in many European wild mammal populations, causing devastating mortality (up to $>90 \%$ ), reported especially from Alpine and Pyrenean chamois, Iberian ibex, aoudad and red fox, whereas only few cases have been reported in the stone marten, badger and roe deer

\footnotetext{
* Corresponding author. Tel.: +86 20 85283730; fax: +86 2085283730 . E-mail address: xingquanzh@scau.edu.cn (X.Q. Zhu).

** Corresponding author. Tel.: +39 11 6709004; fax: +39 116709000. E-mail address: luca.rossi@unito.it (L. Rossi).
}

(Ryser-Degiorgis et al., 2002; González-Candela et al., 2004; Rossi et al., 2007; Oleaga et al., 2008). Apparently, no epidemiological relationship exists, in Europe, between mange foci affecting wild ruminants, wild boars and carnivores. A well-known example is the Alpine chamois in the Western Alps, whose populations have never been affected by this severe condition in spite of long lasting sympatry with affected foxes and wild boars (Berrilli et al., 2002).

The question as to whether Sarcoptes mites infecting different hosts belong to different species or whether they are, in fact, monospecific, has been the subject of an ongoing debate for many years (Zahler et al., 1999; Bornstein et al., 2001; Berrilli et al., 2002; Gu and Yang, 2008). Using microsatellite markers, Walton et al. (1999) substantiated previous data that gene flow between sympatric scabies mite populations on humans and dogs is extremely rare in northern Australia. Likewise, genetic 
differences were detected by microsatellites between geographically distinct populations (Walton et al., 2004; Soglia et al., 2007). Also, microsatellite markers were used by Alasaad et al. (2008a) to describe a new phenomenon of genetic structuring among S. scabiei at individual host skinscale level. On the other hand, Zahler et al. (1999) analysed 23 pooled samples of mite isolates (not single mites) from nine host species in four continents, using the second internal transcribed spacer (ITS-2) of ribosomal DNA (rDNA) as genetic marker, and concluded that Sarcoptes consists of a single, heterogeneous species.

Conversely, using ribosomal and mitochondrial DNA sequences of 28 single Sarcoptes mites from three wild species in Spain and Italy, Berrilli et al. (2002) detected genetic differences between mites derived from red foxes in North Italy and Northwest Spain. The contradiction between the above-mentioned two studies may due to the fact that Zahler et al. (1999) used pooled samples, so genetic variation among individuals may have been underestimated.

The objective of the present study was to examine the genetic characteristics of $S$. scabiei individuals collected from 13 wild mammalian populations representing nine wild animal species in four European countries using ITS-2 as a genetic marker, and to test the effectiveness of ITS-2 rDNA for studying genetic diversity of Sarcoptes mites using relatively a large number of Sarcoptes specimens.

\section{Materials and methods}

\subsection{Collection of S. scabiei}

Using Postponed Isolation (Post-frozen Isolation) and Direct Isolation (Live Isolation) methods, as described by Alasaad et al. (2008c), 148 Sarcoptes mites were collected from the skin of 75 wild animals belonging to nine European wild mammalian species from Switzerland, Italy, France, and Spain (Table 1). Rupicapra rupicapra, Cervus elaphus, Sus scrofa, Ovis aries musimon, Capra ibex, and Vulpes vulpes were sympatric in Northeast Italian Alps. $V$. vulpes and Martes foina were sympatric in Northwest Italian Alps. All mites were identified as S. scabiei based on known morphological criteria (Fain, 1968).

\subsection{Preparation of Sarcoptes gDNA}

HotSHOT Plus ThermalSHOCK technique (Alasaad et al., 2008b) was applied to prepare genomic DNA for all single Sarcoptes mites from Iberian ibex (Sierra Nevada-Spain), while the DNA of single Sarcoptes mite samples from the other hosts were extracted with the NucleoSpin Tissue kit procedure (Macherey-Nagel, Düren, Germany).

\subsection{Amplification and sequencing of the ITS $-2+r D N A$}

The ITS-2 rDNA plus primer flanking $5.8 \mathrm{~S}$ and $28 \mathrm{~S}$ sequences (ITS-2+) was amplified by PCR using primers RIB-18 and RIB-3 as reported previously (Zahler et al., 1999 ) in a 2720 thermal cycler (Applied Biosystems, Foster City, California). The amplicons were examined on $1.5 \%$ agarose gel, stained with ethidium bromide for DNA visualization under UV light. The purified PCR products were directly cycle-sequenced from both directions, on ABI PRISM 310 Genetic Analyser (Applied Biosystems, Foster City, California) using the BigDye Terminator Cycle Sequencing Kit 1.1 (Applied Biosystems, Foster City, California).

Individual mite consensus sequences were manually trimmed of primer sequences, aligned, compared and edited using BioEdit v7.0.9.0 (Hall, 1999). Polymorphic sites were designated with IUPAC codes.

\subsection{Molecular analysis}

Genetic relationships among individual mites was examined using the unweighted pair group method based on arithmetic means (UPGMA; Sneath and Sokal, 1973) in MEGA v. 4 (Tamura et al., 2007), starting from a distance matrix based on the Kimura 2-parameter index (Kimura, 1980), measured by bootstrapping over 1000 replicates, using Notoedres cati (GenBank ${ }^{\mathrm{TM}}$ accession number AF251801) as the out-group, because it is the most closely related taxon to $S$. scabiei. The pairwise comparisons were made of the level of sequence differences (Chilton et al., 1995). Arlequin v.3.1 (Excoffier et al., 2005) was used to calculate the population pairwise Fst (Distance method), Fst $P$ values, and the matrix of significant Fst $P$ values

Table 1

Countries, geographical locations and host species used in this study, together with the number of host animals and Sarcoptes mite samples, followed by GenBank $^{\mathrm{TM}}$ accession numbers for ITS-2+ sequences.

\begin{tabular}{|c|c|c|c|c|c|c|c|c|c|}
\hline Codes & $\begin{array}{l}\text { Countries and } \\
\text { codes }\end{array}$ & & $\begin{array}{l}\text { Geographical locations } \\
\text { and codes }\end{array}$ & & $\begin{array}{l}\text { Host species } \\
\text { and codes }\end{array}$ & & $\begin{array}{l}\text { No. of } \\
\text { animals }\end{array}$ & $\begin{array}{l}\text { No. of } \\
\text { mites }\end{array}$ & $\begin{array}{l}\text { GenBank }^{\mathrm{TM}} \\
\text { accession number }\end{array}$ \\
\hline $\mathrm{Sw} V v$ & Switzerland & Sw & Different locations & & Vulpes vulpes & $V v$ & 13 & 15 & AM980676-AM980690 \\
\hline ItNERr & Italy & It & Northeast & NE & Rupicapra rupicapra & $R r$ & 11 & 33 & AM980691-AM980723 \\
\hline ItNECe & Italy & It & Northeast & NE & Cervus elaphus & $\mathrm{Ce}$ & 1 & 2 & AM980724-AM980725 \\
\hline ItNESs & Italy & It & Northeast & NE & Sus scrofa & Ss & 2 & 6 & AM980726-AM980731 \\
\hline ItNEOam & Italy & It & Northeast & NE & Ovis aries musimon & Oam & 2 & 6 & AM980732-AM980737 \\
\hline ItNECi & Italy & It & Northeast & NE & Capra ibex & $\mathrm{Ci}$ & 2 & 5 & AM980738-AM980742 \\
\hline ItNEV $v$ & Italy & It & Northeast & NE & Vulpes vulpes & $V v$ & 5 & 14 & AM980743-AM980756 \\
\hline ItNWVv & Italy & It & Northwest & NW & Vulpes vulpes & $V v$ & 10 & 26 & AM980757-AM980782 \\
\hline ItNWMf & Italy & It & Northwest & NW & Martes foina & $M f$ & 1 & 3 & AM980783-AM980785 \\
\hline FrNESs & France & $\mathrm{Fr}$ & Northeast & $\mathrm{NE}$ & Sus scrofa & Ss & 3 & 4 & AM980786-AM980789 \\
\hline SpNEVv & Spain & Sp & Northeast & NE & Vulpes vulpes & $V v$ & 1 & 4 & AM980790-AM980793 \\
\hline SpNWRp & Spain & Sp & Northwest & NW & Rupicapra pyrenaica & $R p$ & 3 & 9 & AM980794-AM980802 \\
\hline $\mathrm{SpSCp}$ & Spain & Sp & South & S & Capra pyrenaica & $C p$ & 21 & 21 & AM980803-AM980823 \\
\hline
\end{tabular}


( significance level =0.05) (Weir, 1996; Excoffier et al., 1992). The dendrogram was visualized in the Treelllustrator v. 0.52 Beta software format (Trooskens et al., 2005). Likewise, MEGA v.4 was used to establish the UPGMA tree, showing the genetic relationships among the 13 Sarcoptes populations. The number and frequency of variable sites in different numbers of samples in each population were calculated with F-stat (Goudet, 2001).

\section{Results and discussion}

Individual ITS-2+ sequences were obtained from $148 \mathrm{~S}$. scabiei samples, and deposited in the GenBank ${ }^{\mathrm{TM}}$ (accession numbers AM980676-AM980823). The mean $\mathrm{G}+\mathrm{C}$ content of the sequences was $38.4 \%$. All of the sequences were $404 \mathrm{bp}$ in length, with the exception of two sequences from Italian foxes: ItNWV $v 1 \mathrm{~b}$ had two deletions at the bases number 97 and 98, and ItNEVv2b had one deletion at the base number 321. Sixty-seven variable sites were identified in the sequences obtained (16.59\%, 67/ 404), representing 101 different ITS-2+ sequences (sequence data available from the authors upon request). The number of the variable sites was significantly more than that obtained in other studies where a small number of mites were analyzed (Berrilli et al., 2002; Zahler et al., 1999). It appears that the number of variable sites is related to the magnitude of sample diversity.

The genetic relationships among the individual mites, constructed by UPGMA analysis, showed no specific clustering comprising mites from single host species, nor geographical relation among the 21 resulting clusters (Fig. 1 and Table 2). Mites from different host species and different geographical locations clustered together. As a consequence, mites from the same host species or geographical locations were scattered in different clusters. Mites from the same individual host were even found in different clusters. Likewise, using the population pairwise Fst and the UPGMA tree among populations, no significant

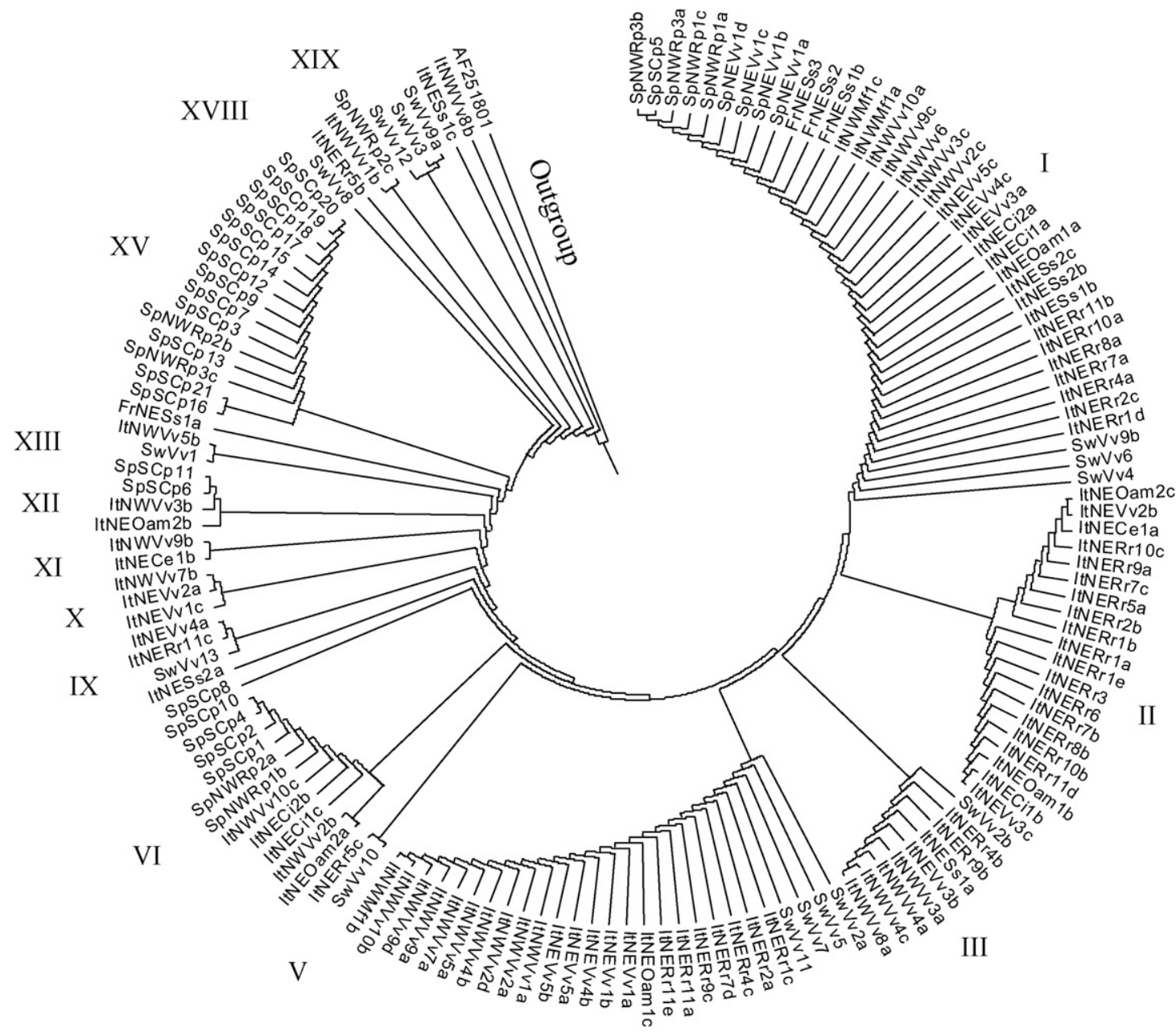

IV

Fig. 1. UPGMA tree showing clustering of the 148 Sarcoptes mites from 13 wild animal populations belonging to nine species in four European countries, based on ITS-2 ribosomal DNA sequences, using Notoedres cati (GenBank ${ }^{\mathrm{TM}}$ accession number AF251801) as the out-group. Clusters are in clockwise order (only clusters with more than one mite are marked). Sarcoptes mites belonging to each cluster are detailed in Table 2 . Codes in this figure represent the sample codes in Table 1. 
Table 2

Twenty-one clusters of the UPGMA tree representing 148 Sarcoptes mites, from 13 wild animal populations representing nine species in four European countries, based on ITS-2 ribosomal DNA sequences, using Notoedres cati (GenBank ${ }^{\mathrm{TM}}$ accession number AF251801) as the outgroup. Codes in this table represent the sample codes in Table 1.

\begin{tabular}{|c|c|}
\hline Clusters & Sarcoptes mites \\
\hline I & $\begin{array}{l}\text { SpNWRp3b, SpSCp5, SpNWRp3a, SpNWRp1c, SpNWRp1a } \\
\text { SpNEVv1d, SpNEVv1c, SpNEVv1b, SpNEVv1a, FrNESs3, } \\
\text { FrNESs2, FrNESs1b, ItNWMf1c, ItNWMf1a, ItNWVv10a, } \\
\text { ItNWVvac, ItNWVv6, ItNWVv3c, ItNWVv2c, ItNEVv5c, } \\
\text { ItNEVv4c, ItNEVv3a, ItNECi2a, ItNECi1a, ItNEOam1a, } \\
\text { ItNESs2c, ItNESs2b, ItNESs1b, ItNERr11b, ItNERr10a, } \\
\text { ItNERr8a, ItNERr7a, ItNERr4a, ItNERr2c, ItNERr1d, } \\
\text { SwVv9b, SwVv6, SwVv4 }\end{array}$ \\
\hline II & $\begin{array}{l}\text { ItNEOam2c, ItNEVv2b, ItNECe1a, ItNERr10c, ItNERr9a, } \\
\text { ItNERr7c, ItNERr5a, ItNERr2b, ItNERr1b, ItNERr1a, } \\
\text { ItNERr1e, ItNERr3, ItNERr6, ItNERr7b, ItNERr8b, } \\
\text { ItNERr10b, ItNERr11d, ItNEOam1b, ItNECi1b, ItNEVv3c }\end{array}$ \\
\hline III & $\begin{array}{l}\text { SwVv2b, ItNERr4b, ItNERr9b, ItNESs1a, ItNEVv3b, } \\
\text { ItNWVv3a, ItNWVv4a, ItNWVv4c, ItNWVv8a }\end{array}$ \\
\hline IV & $\begin{array}{l}\text { SwVv2a, SwVv5, SwVv7, SwVv11, ItNERr1c, ItNERr2a, } \\
\text { ItNERr4c, ItNERr7d, ItNERr9c, ItNERr11a, ItNERr11e, } \\
\text { ItNEOam1c, ItNEVv1a, ItNEVv1b, ItNEVv4b, ItNEVv5a, } \\
\text { ItNEVv5b, ItNWVv1a, ItNWVv2a, ItNWVv2d, ItNWVv4b, } \\
\text { ItNWVv5a, ItNWVv7a, ItNWVv9a, ItNWVv9d, } \\
\text { ItNWVv10b, ItNWMf1b }\end{array}$ \\
\hline V & ItNERr5c, SwVv10 \\
\hline VI & $\begin{array}{l}\text { SpSCp10, SpSCp4, SpSCp2, SpSCp1, SpNWRp2a, } \\
\text { SpNWRp1b, ItNWVv10c, ItNECi2b, ItNECi1c, } \\
\text { ItNWVv2b, ItNEOam2a }\end{array}$ \\
\hline VII & SpScp8 \\
\hline VIII & ItNESs $2 a$ \\
\hline IX & ItNEVv4a, ItNERr11c, SwVv13 \\
\hline $\mathrm{X}$ & ItNWVv7b, ItNEVv2a, ItNEVv1c \\
\hline $\mathrm{XI}$ & ItNWVv9b, ItNECe1b \\
\hline XII & SpSCp11, SpSCp6, ItNWVv3b, ItNEOam2b \\
\hline XIII & ItNWVv5b, SwVv1 \\
\hline XIV & FrNESs1a \\
\hline $\mathrm{XV}$ & $\begin{array}{l}\text { SpSCp20, SpSCp19, SpSCp18, SpSCp17, SpSCp15, } \\
\text { SpSCp14, SpSCp12, SpSCp9, SpSCp7, SpSCp3, } \\
\text { SpNWRp2b, SpSCp13, SpNWRp3c, SpSCp21, SpSCp16 }\end{array}$ \\
\hline XVI & SwVv8 \\
\hline XVII & ItNERr5b \\
\hline XVIII & SpNWRp2c, ItNWVv1b, \\
\hline XIX & SwVv9a, SwVv3, SwVv12 \\
\hline $\mathrm{XX}$ & ItNESs1c \\
\hline XXI & ItNWVv8b \\
\hline Outgroup & AF251801 \\
\hline
\end{tabular}

distance among populations was detected, in agreement with findings of Zahler et al. (1999) and, up to a point, with Berrilli et al. (2002), who reported that only Pyrenean chamois-derived mites formed a separated group. However, in the present study, Pyrenean chamois-derived mites were randomly distributed in different clusters. The discrepancy is likely due to differences in sample sizes among studies.

Forty-six out of the 67 variable sites in the ITS-2+ sequences were observed only in single populations (unique variable sites). The number of variable sites was very different among populations: the population ItNWV $v$ was the most variable (30 mutations), whereas the ItNWMf (4 mutations) and SpNEVv (5 mutations) were the most uniformed mite populations. With the exception of wild boar-derived mites (FrNESs and ItNESs), all populations had two variable sites, namely a $R$ transition in position 68 with an average frequency of $0.21(0.00-0.5)$ and a W transversion in position 272 with an average frequency of $0.34(0.00-0.82)$. In addition, in the French and Italian wild boar-derived mite populations there were some unique variable sites, a transition $\mathrm{R}(0.25)$ and a transversion $\mathrm{W}$ (0.125) for the FrNESs, while three $\mathrm{R}$ transitions $(0.17$ each), a Y transition (0.17), a K transversion (0.08), and a $S$ transversion (0.17) for ItNESs.

Both populations of Spanish wild ruminant mites (SpNWRp and SpSCp) were characterized by two $\mathrm{R}$ transitions and three different transversions MWK, all showing intermediate frequencies, being higher in SpSCp. Italian and Switzerland fox derived mite populations were very variable and shared three transitions ( $R, Y, Y)$ and three transversions (K, M, S) with frequencies clearly higher in SwVv (average 0.16; 0.03-0.26), all absent in Spanish fox derived mites.

ITS-2 rDNA appears to be suitable genetic marker for distinguishing closely related species and examining phylogenetic relationships within genera but not suitable for genetic characterization within a species for mites (Navajas et al., 1994, 1998, 2000; Navajas and Fenton, 2000; Zahler et al., 1998, 1999; Essig et al., 1999; Berrilli et al., 2002). For example, Navajas et al. (1998, 2000) found very low variation in ITS-2 sequences within Tetranychus urticae. Similar patterns of variation were found by Navajas et al. (1994) for Mononychellus progresivus and, as mentioned above, by Zahler et al. (1999) and Berrilli et al. (2002) for Sarcoptes. In addition, Zahler et al. (1998) and Essig et al. (1999) were not able to find clear differences within the worldwide distributed genera Psoroptes and Chorioptes, respectively. However, Navajas et al. (1998) showed extensive polymorphism in sequences of mitochondrial cytochrome oxidase I in T. urticae. Some sorts of geographical or host specificity in Sarcoptes populations have been shown in studies in which microsatellites were used as markers (Walton et al., 2004; Soglia et al., 2007).

In conclusion, ITS-2 rDNA does not appear to be suitable marker for examining genetic diversity among Sarcoptes mite populations. For characterization of sub-populations or strain typing within S. scabiei, genetic markers other than ITS-2 rDNA, such as microsatellite DNA and/or mitochondrial DNA should be used.

\section{Acknowledgements}

The study was supported by MURST contract year 2004, Prot. 2004078701_001 (LR) and a grant by SCI Italian Chapter. The authors thank RNM118 investigation group (Junta de Andalucía-Spain) for supporting SA's investigation stay in Italy. Dr. C. Peral and Prof. S. Lavin kindly supplied skin samples from scabietic Pyrenean chamois. XQZ is supported by the Program for Changjiang Scholars and Innovative Research Team in University (Grant No. IRT0723).

\section{References}

Alasaad, S., Soglia, D., Sarasa, M., Soriguer, R.C., Pérez, J.M., Granados, J.E., Rasero, R., Zhu, X.Q., Rossi, L., 2008a. Skin-scale genetic structure of Sarcoptes scabiei populations from individual hosts: empirical evidence from Iberian ibex-derived mites. Parasitol. Res. 104, 101-105. 
Alasaad, S., Rossi, L., Maione, S., Sartore, S., Soriguer, R.C., Pérez, J.M., Rasero, R., Zhu, X.Q., Soglia, D., 2008b. HotSHOT Plus ThermalSHOCK, a new and efficient technique for preparation of PCR-quality Sarcoptes mite genomic DNA. Parasitol. Res. 103, 1455-1457.

Alasaad, S., Soglia, D., Maione, S., Sartore, S., Soriguer, R.C., Pérez, J.M., Rasero, R., Rossi, L., 2008c. Effectiveness of postponed isolation (postfrozen isolation) method for PCR-quality Sarcoptes mite gDNA. Exp. Appl. Acarol., Oct 15 [Epub ahead of print].

Berrilli, F., D’Amelio, S., Rossi, L., 2002. Ribosomal and mitochondrial DNA sequence variation in Sarcoptes mites from different hosts and geographical regions. Parasitol. Res. 88, 772-777.

Bornstein, S., Mörner, T., Samuel, W.M., 2001. Sarcoptes scabiei and sarcoptic mange. In: Samuel, W.M., Pybus, M.J., Kocan, A.A. (Eds.), Parasitic Diseases of Wild Mammals. Second ed. Iowa State University Press, Ames, pp. 107-119.

Chilton, N.B., Gasser, R.B., Beveridge, I., 1995. Differences in a ribosomal DNA sequence of morphologically indistinguishable species within the Hypodontus macropi complex (Nematoda: Strongyloidea). Int. J. Parasitol. 25, 647-651.

Essig, A., Rinder, H., Gothe, R., Zahler, M., 1999. Genetic differentiation of mites of the genus Chorioptes (Acari: Psoroptidae). Exp. Appl. Acarol. 23, 309-318.

Excoffier, L., Smouse, P.E., Quattro, J.M., 1992. Analysis of molecular variance inferred from metric distances among DNA haplotypes: application to human mitochondrial DNA restriction data. Genetics 131, 479-491.

Excoffier, L., Laval, G., Schneider, S., 2005. ARLEQUIN ver 3. 0: an integrated software package for population genetics data analysis. Evol. Bioinform. Online 1, 47-50.

Fain, A., 1968. Étude de la variabilité de Sarcoptes scabiei avec une revisiondes Sarcoptidae. Acta Zool. Pathol. Antverp. 47, 1-196.

Fain, A., 1978. Epidemiological problems of scabies. Int. J. Dermatol. 17, 20-30.

González-Candela, M., León-Vizcaino, L., Cubero-Pablo, M.J., 2004. Population effects of sarcoptic mange in Barbary sheep (Ammotragus lervia) from Sierra Espuña Regional Park. Spain. J. Wildl. Dis. 40, 456-465.

Goudet, J., 2001. FSTAT, a program to estimate and test gene diversities and fixation indices (version 2.9.3). http://www.unil.ch/izea/softwares/fstat.html.

Gu, X.B., Yang, G.Y., 2008. A study on the genetic relationship of mites in the genus Sarcoptes (Acari: Sarcoptidae) in China. Inter. J. Acarol. 32, $183-190$.

Hall, T.A., 1999. BioEdit: a user friendly biological sequence alignment editor and analysis program for Windows 95/98/NT. Nucleic Acids Symp. Ser. 41, 95-98.

Kimura, M., 1980. A simple method for estimating evolutionary rate of base substitutions through comparative studies of nucleotide sequences. J. Mol. Evol. 16, 111-120.

Navajas, M., Fenton, B., 2000. The application of molecular markers in the study of diversity in acarology: a review. Exp. Appl. Acarol. 24, 751-774.
Navajas, M., Gutierrez, J., Bonato, O., Bolland, H.R., Mapangou-Divassa, S., 1994. Intraspecific diversity of the Cassava Green Mite Mononychellus progresivus (Acari: Tetranychidae) using comparisons of mitochondrial and nuclear ribosomal DNA sequences and cross-breading. Exp. Appl. Acarol. 18, 351-360.

Navajas, M., Lagnel, J., Gutierrez, J., Boursot, P., 1998. Species wide homogeneity of nuclear ribosomal ITS2 sequences in the spider mite Tetranychus urticae contrasts with extensive mitochondrial COI polymorphism. Heredity 80, 742-752.

Navajas, M., Tsagkarakou, A., Lagnel, J., Perrot-Minnot, M.J., 2000. Genetic differentiation in Tetranychus urticae (Acari: Tetranychidae): polymorphism, host races or sibling species? Exp. Appl. Acarol. 24, 365376.

Oleaga, A., Balseiro, A., Gortázar, C., 2008. Sarcoptic mange in two roe deer (Capreolus capreolus) from northern Spain. Eur.J. Wildl. Res. 54, 134-137.

Pence, D.B., Ueckermann, E., 2002. Sarcoptic mange in wildlife. Rev. Sci. Tech. OIE 21, 385-398.

Rossi, L., Fraquelli, C., Vesco, U., Permunian, R., Sommavilla, G.M., Carmignola, G., Da Pozzo, M., Meneguz, P.G., 2007. Descriptive epidemiology of a scabies epidemic in chamois in the Dolomite Alps, Italy. Eur. J. Wildl. Res. 53, 131-141.

Ryser-Degiorgis, M.P., Ryser, A., Bacciarini, L.N., Angst, C., Gottstein, B., Janovsky, M., Breitenmoser, U., 2002. Notoedric and sarcoptic mange in free-ranging lynx from Switzerland. J. Wildl. Dis. 38, 228-232.

Sneath, P.H.A., Sokal, R.R., 1973. Numerical Taxonomy: The Principles and Practice of Numerical Classification. Freeman, San Francisco.

Soglia, D., Rasero, R., Rossi, L., Sartore, S., Sacchi, P., Maione, S., 2007. Microsatellites as markers for comparison among different populations of Sarcoptes scabiei. Ital. J. Anim. Sci. 7, 214-216.

Tamura, K., Dudley, J., Nei, M., Kumar, S., 2007. MEGA4: molecular evolutionary genetics analysis (MEGA) software version 40 . Mol. Biol. Evol. 24, 1596-1599.

Trooskens, G., De Beule, D., Decouttere, F., Van Criekinge, W., 2005. http:// nexus.ugent.be/geert/.

Walton, S.F. Choy, J.L., Bonson, A., Valle, A., McBroom, J., Taplin, D., Arlian, L., Mathews, J.D., Currie, B., Kemp, D.J., 1999. Genetically distinct dogderived and human-derived Sarcoptes scabiei in scabies-endemic communities in northern Australia. Am. J. Trop. Med. Hyg. 61, 542-547.

Walton, S.F., Dougall, A., Pizzutto, S., Holt, D., Taplin, D., Arlian, L.G., Morgan, M., Currie, B.J., Kemp, D.J., 2004. Genetic epidemiology of Sarcoptes scabiei (Acari: Sarcoptidae) in northern Australia. Int. J. Parasitol. 34, 839-849.

Weir, B.S., 1996. Genetic Data Analysis II. Sinauer, Sunderland, MA

Zahler, M., Essig, A., Gothe, R., Rinder, H., 1998. Genetic evidence suggests that Psoroptes isolates of different phenotypes, hosts and geographic origins are conspecific. Int. J. Parasitol. 28, 1713-1719.

Zahler, M., Essig, A., Gothe, R., Rinder, H., 1999. Molecular analyses suggest monospecificity of the genus Sarcoptes (Acari: Sarcoptidae). Int. J. Parasitol. 29, 759-766. 